\title{
ANALISIS PERUBAHAN TARIF PENGHASILAN TIDAK KENA PAJAK (PTKP) TAHUN 2015 DAN TAHUN 2016 TERHADAP PENERIMAAN PAJAK PENGHASILAN (PPH) PASAL 21 DI KANTOR PELAYANAN PAJAK PRATAMA BITUNG
}

\author{
Megawani Lewa ${ }^{1}$, Lintje Kalangi ${ }^{2}$, Winston Pontoh ${ }^{3}$ \\ ${ }^{123}$ Jurusan Akuntansi, Fakultas Ekonomi dan Bisnis, Universitas Sam Ratulangi, Jl. Kampus Bahu, Manado, \\ 95115, Indonesia \\ E-mail : megawanilewa@gmail.com
}

\begin{abstract}
Tax is a compulsory payment to every citizen whose counterpart is not direct. In 2016 there is an Increase in the tariff of Non Taxable Revenue (PTKP). The increase of nontaxable income (PTKP) will be enjoyed by the people who work as employees/employees, and the Taxpayer Object Tax (WPOP) workers who have free and / or self-employed jobs because it will lower taxable income tax (PKP) taxpayers. However, the increase in PTKP has the potential to decrease income tax revenue. This study aims to evaluate the effect of PTKP changes on the acceptance of Income Tax Article 21 in KPP Pratama Bitung. The method used is qualitative descriptive method. The research results show that the non-taxable income $(P T K P)$ experienced a 50\% increase and this affects income tax revenue PPh) significantly. Expected to be able to do things to increase tax revenue from the income tax side of article 21. One of them is to adjust the limits of PTKP with the lowest salary / income of employees. In addition, the Tax Office of Bitung Pratama is also expected to provide continuous supervision and extension on taxpayers of individuals, bodies and treasurers of government offices concerning the awareness of their obligation to withhold tax on income tax on the employee or employees accordingly at the prevailing rate.
\end{abstract}

Keywords: Non Taxable Income, Income Tax, Changes receipts.

\section{PENDAHULUAN}

Pajak merupakan pembayaran/iuran yang diwajibkan kepada setiap warga disuatu negara yang kontraprestasinya tidak bersifat langsung. Penerimaan pajak bagi suatu negara merupakan suatu pos penerimaan yang sangat penting. Direktorat Jenderal Pajak dalam proses menghimpun pajak, menerapkan beberapa aturan dalam menentukan pajak yang harus dibayarkan oleh Wajib Pajak, beberapa diantaranya adalah biaya jabatan, Penghasilan Tidak Kena Pajak (PTKP) dan tarif pajak berlapis yang dikenakan terhadap penghasilan kena pajak Wajib Pajak Orang Pribadi. Fasilitas-fasilitas tersebut diberikan kepada Wajib Pajak Orang Pribadi (WPOP) agar tercipta keadilan pada setiap wajib pajak mulai dari wajib pajak berpenghasilan tinggi sampai dengan wajib pajak yang berpenghasilan menengah kebawah. Selain itu fasilitas tersebut diberikan agar masyarakat tidak terlalu terbebani dengan beban pajak yang harus dibayarnya. Penghasilan Tidak Kena Pajak (PTKP) yang ditetapkan sejak reformasi perpajakan tidak memilki nilai yang tetap, dari tahun 1983 sampai dengan tengah tahun 2016 batasan penghasilan tersebut terus mengalami perubahan. Penetapan besarnya PTKP tersebut telah disesuaikan dengan perkembangan ekonomi dan moneter serta harga kebutuhan pokok yang setiap waktu semakin meningkat. Ditengah perlambatan ekonomi global kebijakan tersebut diambil agar daya beli masyarakat meningkat. PTKP identik dengan standar biaya hidup, berkurangnya pajak penghasilan diharapkan membuat masyarakat bisa menikmati lebih banyak penghasilannya dalam bentuk konsumsi maupun saving/tabungan. 
Dengan begitu pemasukan dari jenis pajak yang lain seperti PPN (Pajak Pertambahan Nilai) dan pajak atas bunga dari saving/tabungan akan meningkat (Andiyanto, 2014).

Pada tahun 2016, Menteri Keuangan menerbitkan Peraturan Menteri Keuangan No. 101/PMK.010/2016 tentang Penyesuaian Besarnya Penghasilan Tidak Kena Pajak yang berlaku efektif mulai tanggal 27 Juni 2016 untuk menggantikan Peraturan Menteri Keuangan Nomor 122/PMK.010/2015 tentang Penyesuaian Besarnya Penghasilan Tidak Kena Pajak tanggal 29 Juni 2015. Pada peraturan Menteri Keuangan Republik Indonesia tahun 2016, PTKP wajib pajak mengalami peningkatan jumlah yang signifikan dibandingkan dengan PTKP tahun 2015. Kenaikan Penghasilan Tidak Kena Pajak (PTKP) ini akan dinikmati oleh masyarakat yang berkerja sebagai karyawan/pegawai, dan buruh maupun WPOP yang memiliki pekerjaan bebas dan/atau wiraswasta. PTKP yang disesuaikan oleh Direktorat Jendral Pajak (DJP) tersebut berada diatas Upah Minimum Provinsi (UMP). Upah Minimum Provinsi Sulawesi Utara berdasarkan Peraturan Gubenur Nomor 37 Tahun 2015 yang berlaku mulai tanggal 1 Januari 2016 dengan nilai besaran upah sebesar Rp. 2.400.000,- setiap bulannya mengakibatkan masyarakat yang bekerja sebagai karyawan/pegawai dan buruh di Provinsi Sulawesi Utara dapat melaporkan SPT dengan pajak yang harus dibayar sebesar Rp. 0,- atau nihil, apabila penghasilan tersebut telah atau tanpa diakumulasi dengan tunjangan namun tetap dibawah PTKP.

Pajak penghasilan pasal 21 yang dikenakan kepada para karyawan merupakan pajak yang bersifat withholding system sehingga tingkat ketertagihannya menjadi tinggi dan mudah melakukan penelusuran. Peningkatan Penghasilan Tidak Kena Pajak (PTKP) dapat menurunkan penerimaan pajak penghasilan $(\mathrm{PPh})$, tetapi berpotensi meningkatkan penghasilan/pendapatan masyarakat/wajib pajak, sehingga diharapkan dapat meningkatkan belanja masyarakat. Karena itu penelitian ini dilakukan untuk menganalisis Perubahan Tarif Penghasilan Tidak Kena Pajak (PTKP) Terhadap Penerimaan Pajak Penghasilan (PPh) Pasal 21 di Kantor Pelayanan Pajak Pratama Bitung. Tujuan penelitian ini untuk mengetahui pengaruh perubahan tarif PTKP terhadap penerimaan PPh Pasal 21 di KPP Pratama Bitung.

\section{TINJAUAN PUSTAKA}

\subsection{Akuntansi Pajak}

\section{Definisi Akuntansi Pajak}

Pengertian akuntansi menurut Wild \& Kwok (2011:4) dalam Agoes dan Estralita (2013:1) merupakan sistem informasi yang menghasilkan laporan kepada pihak yang berkepentingan mengenai aktivitas ekonomi dan kondisi perusahaan. Sedangkan akuntansi pajak adalah menetapkan besarnya pajak terutang berdasarkan laporan keuangan yang disusun oleh perusahaan.

\section{Tujuan Akuntansi Pajak}

Akuntansi pajak digunakan untuk mempermudah penyusunan Surat Pemberitahuan Pajak (SPT) Masa dan Tahunan Pajak Penghasilan ke Kantor Pelayanan Pajak (KPP) dimana Wajib Pajak tersebut terdaftar. SPT Tahunan Pajak Penghasilan harus diisi sesuai dengan laporan keuangan fiskal dan harus dilampirkan antara akuntansi komersial dengan akuntansi pajak. Terdapat perbedaan kebijakan dalam hal pengakuan pendapatan dan biaya, hal ini dapat mengakibatkan besarnya pajak terutang antara akuntansi komersial dengan akuntasi pajak berbeda (Tunggal, 2012:6).

\subsection{Pajak}

\section{Definisi Pajak}

Menurut Mardiasmo (2016:3) adalah pembayaran/iuran rakyat atau masyarakat kepada kas negara berdasarkan undang-undang atau peraturan yang berlaku (yang dapat dipaksa) dengan tidak mendapat jasa timbal (kontraprestasi) yang langsung dapat digunakan untuk membayar pengeluaran/anggaran umum negara. 


\section{Fungsi Pajak}

Fungsi pajak menurut Resmi (2013:3) yaitu:

1. Fungsi Penerimaan (Budgetair)

Berfungsi sebagai sumber dana yang akan diperuntukkan bagi pembiayaan/pengeluaran pemerintah.

2. Fungsi Mengatur (Regulerend)

Berfungsi sebagai alat untuk mengatur/melaksanakan kebijakan di bidang sosial maupun perekonomian.

\section{Jenis Pajak}

Menurut Waluyo (2011:12) dan Resmi (2013:7) pajak dapat dikelompokkan ke dalam tiga kelompok, adalah sebagai berikut:

1. Menurut golongan atau pembebanan

2. Menurut sifat

3. Menurut pemungut dan pengelolanya

\subsection{Penghasilan Tidak Kena Pajak (PTKP)}

\section{Definisi Penghasilan Tidak Kena Pajak}

Menurut Gunawan (2016), Penghasilan Tidak Kena Pajak (PTKP) merupakan faktor pengurangan pada penghasilan/pendapatan orang pribadi/perseorangan/karyawan sebagai wajib pajak (WP) dalam negeri, dalam menghitung Penghasilan Kena Pajak (PKP) yang akan menjadi objek pajak penghasilan yang harus dibayar Wajib Pajak (perseorangan/orang pribadi) di Indonesia.

\section{Tarif Penghasilan Tidak Kena Pajak}

Dalam Peraturan Menteri Keuangan Republik Indonesia Nomor 101/PMK.010/2016 tentang penyesuaian besarnya Penghasilan Tidak Kena Pajak (PTKP). Besarnya tarif Penghasilan Tidak Kena Pajak (PTKP) adalah:

Tabel 1. Tarif Penghasilan Tidak Kena Pajak Tahun 2015 dan Tahun 2016

\begin{tabular}{lccr}
\hline \multicolumn{1}{c}{ Uraian } & Status & $\begin{array}{c}\text { Tarif PTKP } \\
\text { 2015 }(\mathrm{Rp})\end{array}$ & $\begin{array}{c}\text { Tarif PTKP } \\
\text { 2016 (Rp) }\end{array}$ \\
\hline Wajib Pajak (WP) & TK/0 & 36.000 .000 & 54.000 .000 \\
WP + Tanggungan 1 & TK/1 & 39.000 .000 & 58.500 .000 \\
WP + Tanggungan 2 & TK/2 & 42.000 .000 & 63.000 .000 \\
WP + Tanggungan 3 & TK/3 & 45.000 .000 & 67.500 .000 \\
WP Kawin (K) & K/0 & 39.000 .000 & 58.500 .000 \\
K + Tanggungan 1 & K/1 & 42.000 .000 & 63.000 .000 \\
K + Tanggungan 2 & K/2 & 45.000 .000 & 67.500 .000 \\
K + Tanggungan 3 & K/3 & 48.000 .000 & 72.000 .000 \\
\hline
\end{tabular}

\subsection{Pajak Penghasilan Pasal 21}

\section{Definisi Pajak Penghasilan Pasal 21}

Menurut Sari (2013:25), Pajak Penghasilan Pasal 21 adalah PPh yang harus dipotong oleh setiap pemberi kerja terhadap imbalan berupa gaji, upah, honorarium, tunjangan, penghargaan, maupun pembayaran lainnya, yang mereka bayar atau terutang kepada orang pribadi dalam negeri sehubungan dengan pekerjaan, jasa dan kegiatan yang dilakukan orang pribadi tersebut.

\section{Perhitungan Pajak Penghasilan Pasal 21}

Menurut Gunawan (2016), Pajak Penghasilan Pasal 21 yang dipotong oleh pemotong pajak secara umum diformulasikan sebagai berikut:

Pajak Penghasilan Pasal 21 = Tarif Dasar x Penghasilan Kena Pajak (PKP)

Gambar 1. Perhitungan Pajak Penghasilan Pasal 21 


\subsection{Penelitian Terdahulu}

1. Nuritomo (2011) meneliti Pengaruh Peningkatan Penghasilan Tidak Kena Pajak Terhadap Penerimaan Pajak Studi Pada KPP Pratama Yogyakarta Satu. Metode yang digunakan dalam penelitian ini adalah pendekatan kualitatif yang bersifat deskriptif. Hasil penelitian menunjukkan bahwa peningkatan Penghasilan Tidak kena Pajak (PTKP) memberikan pengaruh yang besar terhadap penerimaan pajak penghasilan $(\mathrm{PPh})$ pasal 21. Penerimaan pajak penghasilan (PPh) pasal 21 mengalami penurunan dengan persentase sebesar 26,04\% dengan diberlakukannya PTKP baru ini.

2. Dimas Andiyanto (2014) meneliti Analisis Perubahan Penghasilan Tidak Kena Pajak (PTKP) Terhadap Tingkat Pertumbuhan Jumlah Wajib Pajak Orang Pribadi Dan Penerimaan Pajak Penghasilan (Studi Pada KPP Pratama Malang Selatan Dan KPP Pratama Banyuwangi Periode 2009-2013). Metode yang digunakan dalam penelitian ini adalah pendekatan deskriptif kualitatif dan Hasil penelitian menunjukkan bahwa perubahan (kenaikan) PTKP mengakibatkan tingkat penerimaan pajak penghasilan pasal 21 (Wajib Pajak karyawan, pegawai, buruh) di KPP Pratama Malang Selatan turun, yang terlihat dari realisasi penerimaan tahun 2013 lebih kecil dari pada tahun 2012 dengan penurunan sebesar 10\%, namun sebaliknya di KPP Pratama Banyuwangi, perubahan PTKP tidak mengakibatkan penurunan realisasi penerimaan Pajak Penghasilan Pasal 21, realisasi penerimaan pada tahun 2013 justru mengalami kenaikan 30\% lebih tinggi dibandingkan realisasi tahun 2012.

\section{METODE PENELITIAN}

\subsection{Jenis Penelitian}

Penelitian ini menggunakan penelitian kualitatif dengan pendekatan deskriptif, yaitu peneliti melakukan analisis-analisis, yang menjelaskan atau mentransformasikan, menterjemahkan, dan menjelaskan makna data atau fenomena-fenomena yang didapati secara langsung. Lokasi penelitian yaitu Kantor Pelayanan Pajak Pratama Bitung. Penelitian ini berlangsung pada bulan Desember 2017 sampai dengan Mei 2018.

\subsection{Prosedur Penelitian}

Prosedur yang dilaksanakan dalam penelitian ini dijabarkan dalam gambar berikut ini:

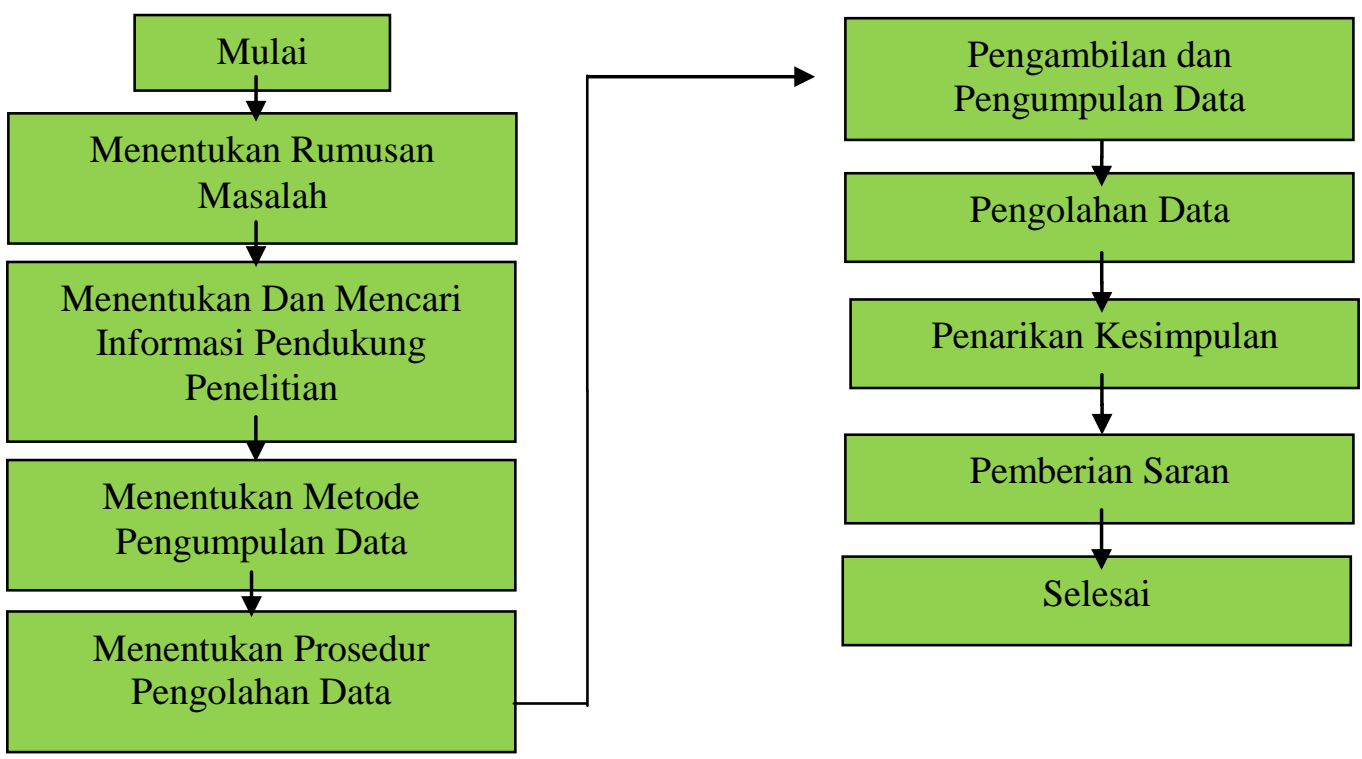

Gambar 2. Prosedur Penelitian Sumber: Kerangka Berpikir Penelitian 


\subsection{Metode Pengumpulan Data}

Teknik pengumpulan data dalam penelitian ini adalah:

1. Penelitian Langsung (Field Research)

Studi lapangan adalah melakukan peninjauan secara langsung untuk memperoleh data-data yang diperlukan dalam penyusunan penelitian. Teknik penelitian langsung ini berupa tehnik dokumentasi, yaitu mengumpulkan bahan-bahan yang tertulis berupa data. Teknik dokumentasi yang digunakan dalam penelitian ini untuk mengetahui data perubahan PTKP dan penerimaan PPh Pasal 21 pada saat prapenelitian. Selain itu, dokumentasi digunakan sebagai pengumpulan data gambaran pelaksanaan penelitian yang dilaksanakan.

2. Studi Pustaka (Library Research)

Studi pustaka adalah teknik pengumpulan data berbagai bahan pustaka (referensi) yang relevan dan mempelajari semua yang berkaitan dengan semua masalah yang akan dibahas. Data yang diperoleh melalui studi kepustakaan merupakan sumber yang ditemukan oleh para ahli yang kompeten dalam bidangnya masing-masing sehingga relevan dengan pembahasan yang sedang diteliti, dalam melakukan studi kepustakaan beberapa hal dilakukan dalam mengumpulkan data yaitu sebagai berikut:

a. Mempelajari konsep dan teori dari berbagai sumber yang berhubungan dan mendukung pada masalah yang sedang diteliti.

b. Mempelajari materi kuliah dan bahan tertulis lainnya.

\subsection{Metode Analisis}

Metode yang digunakan dalam penelitian ini adalah metode analisis deskriptif yaitu suatu metode pembahasan permasalahan yang sifatnya menguraikan, menggambarkan, membandingkan, dan menerangkan suatu data atau keadaan yang sedemikian rupa sehingga dapat ditarik kesimpulannya untuk mencapai tujuan penelitian yang diinginkan.

\section{HASIL PENELITIAN DAN PEMBAHASAN}

\subsection{Hasil Penelitian}

\section{Tarif Penghasilan Tidak Kena Pajak (PTKP) Kota Bitung}

Tarif Pajak Penghasilan Tidak Kena Pajak (PTKP) yang berlaku pada masa tahun 2015 sampai dengan 2017 pada Kota Bitung tertuang pada Tabel 2 sebagai berikut:

Tabel 2. Tarif Penghasilan Tidak Kena Pajak Tahun 2015 Sampai Dengan Tahun 2017

\begin{tabular}{lcccc}
\hline \multicolumn{1}{c}{ Uraian } & Status & $\begin{array}{c}\text { Tarif PTKP } \\
\text { 2015 }(\mathrm{Rp})\end{array}$ & $\begin{array}{c}\text { Tarif PTKP } \\
\text { 2016 }(\mathrm{Rp})\end{array}$ & $\begin{array}{c}\text { Tarif PTKP } \\
2017(\mathrm{Rp})\end{array}$ \\
\hline Wajib Pajak (WP) & $\mathrm{TK} / 0$ & 36.000 .000 & 54.000 .000 & 54.000 .000 \\
WP + Tanggungan 1 & $\mathrm{TK} / 1$ & 39.000 .000 & 58.500 .000 & 58.500 .000 \\
WP + Tanggungan 2 & $\mathrm{TK} / 2$ & 42.000 .000 & 63.000 .000 & 63.000 .000 \\
WP + Tanggungan 3 & $\mathrm{TK} / 3$ & 45.000 .000 & 67.500 .000 & 67.500 .000 \\
WP Kawin (K) & $\mathrm{K} / 0$ & 39.000 .000 & 58.500 .000 & 58.500 .000 \\
K + Tanggungan 1 & $\mathrm{K} / 1$ & 42.000 .000 & 63.000 .000 & 63.000 .000 \\
K + Tanggungan 2 & $\mathrm{K} / 2$ & 45.000 .000 & 67.500 .000 & 67.500 .000 \\
K + Tanggungan 3 & $\mathrm{K} / 3$ & 48.000 .000 & 72.000 .000 & 72.000 .000 \\
\hline
\end{tabular}

Tabel 2 diatas dapat dilihat Penghasilan Tidak Kena Pajak (PTKP) tahun 2016 mengalami kenaikan sebesar 50\% dari Penghasilan Tidak Kena Pajak tahun 2015.

\section{Jumlah Penerimaan PPh Pasal 21 KPP Pratama Bitung}

Penerimaan Pajak Penghasilan dari tahun ke tahun selalu mengalami pergerakan baik menurun maupun meningkat. Capaian penerimaan Pajak Penghasilan diukur 
dengan Target dan Realisasi per tahun. Hasil capaian tahunan ini yang akan jadi ukuran keberhasilan Penerimaan Pajak Penghasilan pada masa pajak tersebut. Untuk Penerimaan Pajak Penghasilan pada KPP Pratama Bitung dijabarkan dalam Tabel 3.

Tabel 3. Jumlah Penerimaan PPh Pasal 21 Tahun 2015 - 2017

\begin{tabular}{|c|c|c|c|c|}
\hline Tahun & Target & Realisasi & $\begin{array}{c}\text { Capaian } \\
(\%)\end{array}$ & $\begin{array}{c}\text { Kenaikan/Penurunan } \\
\text { Penerimaan PPh }\end{array}$ \\
\hline 2015 & 134.357 .908 .839 & 154.811 .308 .942 & 115,22 & - \\
\hline 2016 & 177.134 .492 .000 & 156.474 .478 .628 & 88,34 & Rp. 1.663.169.686,- \\
\hline 2017 & 201.928 .466 .000 & 143.267 .703 .816 & 70,95 & (Rp. 13.206.774.812,-) \\
\hline
\end{tabular}

Berdasarkan tabel 3 diatas dapat diketahui bahwa jumlah target penerimaan $\mathrm{PPh}$ Pasal 21 dari tahun 2015 sampai dengan tahun 2017 mengalami penurunan. Tahun 2015 realisasi sebesar Rp. 154.811.308.942,- dengan target sebesar Rp. 134.357.908.839,- maka capaian tahun 2015 sebesar 115,22\%. Sedangkan Tahun 2016 realisasi penerimaan $\mathrm{PPh}$ Pasal 21 sebesar Rp. 156.474.478.628,- tidak mencapai target yang telah ditentukan yaitu Rp. 177.134.492.000,- dengan capaian sebesar $88,34 \%$. Demikian juga pada tahun 2017 , realisasi penerimaan PPh Pasal 21 adalah sebesar Rp. 143.267.703.816,- atau 70,95\% dari target yang ditentukan yaitu Rp. 201.928.466.000,-.

Untuk penerimaan $\mathrm{PPh}$ dilihat dari realisasi penerimaan tahunan mengalami kenaikan pada tahun 2016, dimana realisasi penerimaan tahun 2015 sebesar Rp. 154.811.308.942,- dan realisasi penerimaan tahun 2016 sebesar $\mathrm{Rp}$. 156.474.478.628,- dengan jumlah kenaikan sebesar Rp. 1.663.169.686,- dari penerimaan tahun 2015. Realisasi penerimaan tahun 2017 mengalami penurunan dari tahun 2016 sebesar Rp. 13.206.774.812,- dimana realisasi penerimaan tahun 2017 sebesar Rp. 143.267.703.816,-..

\subsection{Pembahasan}

\section{Tarif Penghasilan Tidak Kena Pajak (PTKP)}

Pada Tabel 2 menunjukan Penghasilan Tidak Kena Pajak yang berlaku pada masa pajak KPP Pratama Bitung periode 2015 sampai tahun 2017. Terlihat bahwa Penghasilan Tidak Kena Pajak pada tahun 2015 ke tahun 2016 mengalami perubahan sedangkan tahun 2016 sampai tahun 2017 tidak mengalami perubahan. Perhitungan persentase peningkatan dihitung berdasarkan perhitungan matematis seperti berikut:

$\%$ Kenaikan $=\frac{\text { tahun tertentu }- \text { tahun dasar }}{\text { tahun dasar }} \times 100$

Untuk menghitung persentase kenaikan pada tahun 2015 ke tahun 2016 sebagai contoh diambil Wajib Pajak dengan status Tidak Kawin tanpa tanggungan (TK/0) dengan Tarif Penghasilan Tidak Kena Pajak (PTKP) tahun 2015 sebesar Rp. 36.000.000,- dan pada tahun 2016 sebesar Rp. 54.000.000,- sehingga persentase kenaikan adalah sebagai berikut: 


$\begin{aligned} \% \text { Kenaikan } & =\frac{\text { Rp. } 54.000 .000-\text { Rp. } 36.000 .000}{\text { Rp. } 36.000 .000} \\ & =\frac{\text { Rp. } 18.000 .000}{\text { Rp. } 36.000 .000} \times 100 \\ & =50 \%\end{aligned}$

Nilai 50\% kenaikan Penghasilan Tidak Kena Pajak (PTKP) tersebut berlaku untuk semua status Wajib Pajak yaitu status wajib pajak Tidak Kawin Tanpa Tanggungan (TK/0), Tidak Kawin Tanggungan 1 (TK/1), Tidak Kawin Tanggungan $2(\mathrm{TK} / 2)$, Tidak Kawin Tanggungan $3(\mathrm{TK} / 3)$, Kawin Tanpa Tanggungan (K/0), Kawin Anak $1(\mathrm{~K} / 1)$, Kawin Anak $2(\mathrm{~K} / 2)$, dan Kawin Anak $3(\mathrm{~K} / 3)$.

2. Penerimaan PPh Pasal 21

Apabila dihitung perubahan terhadap besaran Penghasilan Tidak Kena Pajak (PTKP) pada masing-masing Wajib Pajak yang ada maka akan menurunkan penerimaan pajak, seperti yang di tampilkan pada tabel 4 besarnya gaji setahun Wajib Pajak sebesar Rp. 53.038.714,- pada tahun 2015 memiliki Penghasilan Kena Pajak (PKP) namun dengan perubahan PTKP di tahun 2016 membuat pelaporan Penghasilan Kena Pajak (PKP) tahun 2016 Nihil. Tabel 4 dibawah ini menampilkan simulasi Pajak Penghasilan Pasal 21 (PPh 21) tahun 2015 dan tahun 2016:

Tabel 4. Simulasi PPh pasal 21

\begin{tabular}{|c|c|c|c|c|c|c|}
\hline \multirow[b]{2}{*}{ No. } & \multirow[b]{2}{*}{$\begin{array}{c}\text { Gaji } \\
\text { Setahun }\end{array}$} & \multirow[b]{2}{*}{$\begin{array}{l}\text { Status } \\
\text { Kawin }\end{array}$} & \multicolumn{2}{|c|}{2015} & \multicolumn{2}{|c|}{2016} \\
\hline & & & $\begin{array}{l}\text { Jumlah } \\
\text { PTKP }\end{array}$ & $\begin{array}{c}\text { PPh } 21 \\
\text { Setahun }\end{array}$ & $\begin{array}{c}\text { Jumlah } \\
\text { PTKP }\end{array}$ & $\begin{array}{c}\text { PPh } 21 \\
\text { Setahun }\end{array}$ \\
\hline 1 & 53.038 .714 & $\mathrm{~K} / 0$ & 39.000 .000 & 701.900 & 58.500 .000 & 0 \\
\hline 2 & 66.308 .343 & $\mathrm{~K} / 2$ & 45.000 .000 & 1.065 .400 & 67.500 .000 & 0 \\
\hline 3 & 57.155 .784 & $\mathrm{~K} / 1$ & 42.000 .000 & 757.750 & 63.000 .000 & 0 \\
\hline 4 & 42.177 .362 & $\mathrm{~K} / 2$ & 45.000 .000 & 0 & 67.500 .000 & 0 \\
\hline 5 & 70.551 .039 & $\mathrm{~K} / 1$ & 42.000 .000 & 1.427 .550 & 63.000 .000 & 377.550 \\
\hline 6 & 65.465 .840 & $\mathrm{~K} / 0$ & 39.000 .000 & 1.323 .250 & 58.500 .000 & 348.250 \\
\hline 7 & 50.348 .775 & $\mathrm{TK} / 0$ & 36.000 .000 & 717.400 & 54.000 .000 & 0 \\
\hline 8 & 65.465 .840 & $\mathrm{~K} / 0$ & 39.000 .000 & 1.323 .250 & 58.500 .000 & 348.250 \\
\hline 9 & 56.676 .456 & $\mathrm{~K} / 0$ & 39.000 .000 & 883.800 & 58.500 .000 & 0 \\
\hline \multirow[t]{2}{*}{10} & 54.355 .238 & TK/0 & 36.000 .000 & 917.750 & 54.000 .000 & 17.750 \\
\hline & & & Jumlah & 9.118 .050 & & 1.091 .800 \\
\hline
\end{tabular}

\section{Sumber: Data Hasil Olahan, 2018}

Berdasarkan Tabel 4 dapat diketahui bahwa jumlah gaji setahun pegawai nomor 1 dengan status kawin K/0 (kawin anak 0) adalah sebesar Rp. 53.038.714,-. Jumlah potongan PPh Pasal 21 setelah dikurangi PTKP tahun 2015 adalah sebesar Rp. 701.900,- namun saat menggunakan PTKP tahun 2016 pegawai nomor 1 tidak dipotong PPh Pasal 21 karena jumlah gaji setahun tidak melebihi PTKP. Demikian juga jumlah gaji setahun pegawai nomor 5 dengan status kawin K/1 
(kawin anak 1) adalah sebesar Rp. 70.551.039,-. Jumlah potongan PPh Pasal 21 setelah dikurangi PTKP tahun 2015 adalah sebesar Rp. 1.427.550,- namun saat menggunakan PTKP tahun 2016 jumlah potongan $\mathrm{PPh}$ Pasal 21 pegawai nomor 5 mengalami penurunan menjadi Rp. 377.550,-.

3. Analisis Perubahan Penghasilan Tidak Kena Pajak (PTKP) terhadap Penerimaan Pajak Penghasilan (PPh) Pasal 21

Pada tahun 2016 realisasi penerimaan pajak penghasilan pasal 21 yang diterima KPP Pratama Bitung sebesar Rp. 156.474.478.628,- mengalami penurunan sebesar 26,88\% atau senilai Rp. 20.660.013.372.- dari target yang ditentukan yaitu sebesar Rp. 177.134.492.000,-. Sedangkan untuk tahun 2015 realisasi yang diterima sebesar Rp. 154.811.308.942,- dari target yang ditentukan sebesar Rp.134.357.908.839,-. Dilihat dari realisasi tahun 2015 dan 2016 penurunan penerimaan Pajak Penghasilan tidak begitu besar. Hal ini disebabkan karena Pelaporan Surat Pemberitahuan Tahunan (SPT) tahun 2015 memiliki masa periode sampai dengan 31 Maret 2016 atau akhir bulan ketiga setelah berakhirnya tahun atau bagian tahun pajak diatur dalam PMK-243/PMK.03/2014 Peraturan Pajak. Sehingga penerimaan Pajak Penghasilan tahun 2016 masih terakumulasi dengan penerimaan tahun 2015. Penurunan yang signifikan terlihat pada tahun 2017 dimana realisasi yang dicapai sebesar Rp. 143.267.703.816,- dari target yang ditentukan sebesar Rp. 201.928.466.000,- dengan presentase pencapaian 70,95\%. Peraturan Menteri Keuangan Nomor 101/KMK.010/2016 tentang Penyesuaian Besarnya Penghasilan Tidak Kena Pajak membuat penerimaan Pajak Penghasilan menurun di tahun 2016 dan berpengaruh yang besar terhadap penurunan realisasi penerimaan PPh Pasal 21 tahun 2017.

Pada simulasi di atas dapat dilihat bahwa jumlah gaji setahun pegawai nomor 1 dengan status kawin K/0 (kawin anak 0) adalah sebesar Rp. 53.038.714,-. Jumlah potongan PPh Pasal 21 setelah dikurangi PTKP tahun 2015 adalah sebesar Rp. 701.900,- namun pada saat menggunakan PTKP tahun 2016 pegawai nomor 1 tidak dipotong PPh Pasal 21 atau mengalami penurunan sebesar $100 \%$. Hal ini disebabkan oleh karena gaji setahun pegawai tersebut tidak melebihi PTKP tahun 2016. Demikian juga jumlah gaji setahun pegawai nomor 5 dengan status kawin $\mathrm{K} / 1$ (kawin anak 1) adalah sebesar Rp. 70.551.039,-. Jumlah potongan PPh Pasal 21 setelah dikurangi PTKP tahun 2015 adalah sebesar Rp. 1.427.550,- namun saat menggunakan PTKP tahun 2016 jumlah potongan $\mathrm{PPh}$ Pasal 21 pegawai nomor 5 mengalami penurunan menjadi Rp. 377.550,- atau sebesar $73 \%$. Hal ini disebabkan oleh karena jumlah PTKP tahun 2016 untuk status kawin pegawai tersebut mengalami kenaikan sehingga mengurangi pajak penghasilan pasal 21 . Tabel 4 menunjukan akumulasi Pajak Penghasilan pasal 21 dengan nilai Penghasilan Tidak Kena Pajak (PTKP) yang berlaku tahun 2015 memiiki Penerimaan Pajak sebesar Rp. 9.118.050,- sedangkan dengan status dan penghasilan yang sama diberlakukan di tahun 2016 dengan perubahan nilai Penghasilan Tidak Kena Pajak (PTKP) menghasilkan penerimaan Pajak Penghasilan (PPh 21) sebesar Rp. 1.091.800,-. Hal ini menunjukan penurunan penerimaan Pajak Penghasilan pasal 21 secara signifikan yaitu sebesar 11,97\%. Penurunan penerimaan Pajak Penghasilan dibuktikan juga dalam capaian target dan realisasi Pajak Penghasilan (dalam Tabel 3).

\section{KESIMPULAN DAN SARAN}

\subsection{Kesimpulan}

Kesimpulan yang dapat ditarik dari penelitian ini adalah sebagai berikut: 
1. Perubahan PTKP menurunkan capaian realisasi Pajak Penghasilan $(\mathrm{PPh})$ tahun 2016 dan tahun 2017, dimana tahun 2015 capaian realisasi mencapai 115,22\% namun pada tahun 2016 capaian realisasi $\mathrm{PPh}$ yang diterima sebesar $\mathrm{Rp}$. 156.474.478.628,- dari target yang ditentukan sebesar Rp. 177.134.492.000,dengan persentase sebesar 88,34\% . Dan tahun 2017 capaian realisasi $\mathrm{PPh}$ sebesar Rp. 143.267.703.816,- dari target yang ditentukan sebesar Rp. 201.928.466.000,- dengan jumlah persentase sebesar 70,95\%. Untuk penerimaan $\mathrm{PPh}$ dilihat dari realisasi penerimaan tahunan mengalami kenaikan pada tahun 2016, dimana realisasi penerimaan tahun 2015 sebesar Rp. 154.811.308.942,- dan realisasi penerimaan tahun 2016 sebesar Rp. 156.474.478.628,- dengan jumlah kenaikan sebesar Rp. 1.663.169.686,- dari penerimaan tahun 2015. Realisasi penerimaan tahun 2017 mengalami penurunan dari tahun 2016 sebesar Rp. 13.206.774.812,- dimana realisasi penerimaan tahun 2017 sebesar Rp. 143.267.703.816,-.

2. Pemerintah dapat membangun kepercayaan masyarakat terhadap perpajakan, serta meyakinkan masyarakatnya untuk turut membangun Negara dalam hal pembayaran pajak.

3. Direktorat Jendral Pajak (DJP) harus lebih giat untuk mengajak masyarakat yang berpotensi pajak yang belum mempunyai NPWP bahkan yang tidak membayar pajak, untuk mendaftarkan dirinya serta membayarkan pajak penghasilannya.

\subsection{Saran}

Berdasarkan hasil penelitian ini, maka saran-saran yang dapat diberikan oleh peneliti adalah:

1. Bagi Kantor Pelayanan Pajak Pratama Bitung.

Diharapkan agar mampu harus melakukan hal-hal guna meningkatkan penerimaan pajak dari sisi pajak penghasilan pasal 21. Salah satunya adalah dengan menyesuaikan batasan PTKP dengan batasan gaji/penghasilan terendah pegawai. Namun disamping itu juga, Kantor Pelayanan Pajak Pratama Bitung juga diharapkan tetap memberikan pengawasan dan penyuluhan yang berkesinambungan pada wajib pajak orang pribadi, badan dan bendaharawan kantor-kantor pemerintah mengenai kesadaran akan kewajibannya dalam melakukan pemotongan/pemungutan pajak penghasilan pasal 21 atas pegawai atau karyawannya sesuai dengan tarif yang berlaku.

2. Bagi Peneliti Selanjutnya

Peneliti selanjutnya disarankan agar menambah variabel independen, dependen, moderating, intervening yang memiliki kemungkinan untuk berpengaruh terhadap hubungan antara penghasilan tidak kena pajak dan penerimaan pajak penghasilan pasal 21.

\section{DAFTAR PUSTAKA}

Agoes, Sukrisno dan Estralita. 2013. Akuntansi Perpajakan, Edisi 3. Jakarta: Salemba Empat. Andiyanto, Dimas. 2014. Analisis Perubahan Penghasilan Tidak Kena Pajak (PTKP) Terhadap Tingkat Pertumbuhan Jumlah Wajib Pajak Orang Pribadi Dan Penerimaan Pajak Penghasilan (Studi Pada KPP Pratama Malang Selatan Dan KPP Pratama Banyuwangi Periode 2009-2013). Jurnal Mahasiswa Perpajakan, 2(1).

Direktorat Jenderal Pajak, 2016. Bendahara Mahir Pajak Edisi Revisi 2016.

Gunawan, Anggi. 2016. Pengaruh Perubahan Penghasilan Tidak Kena Pajak (PTKP) Terhadap Penerimaan Pajak Penghasilan (PPh) Pasal 21 (Studi Kasus pada Kantor 
Wilayah DJP Jawa Barat I periode 2012-2015). Skripsi. Universitas Widyatama, Bandung.

Kementerian Keuangan RI, 2015. Aturan Pemerintah RI (Republik Indonesia) Nomor 30 (Tiga Puluh) Tahun 2015 mengenai Perubahan Ke 17 (Tujuh belas) terhadap Peraturan Pemerintah Nomor 7 (Tujuh) Tahun 1977 mengenai Peraturan Pendapatan/Gaji Pegawai Negeri.

Kementerian Keuangan RI, 2016. Peraturan Menteri Keuangan RI (Republik Indonesia) No. 101/PMK.010/2016 mengenai Penyesuaian Besarnya Penghasilan Tidak Kena Pajak (PTKP).

Mardiasmo. 2016. Perpajakan Edisi Terbaru 2016. Yogyakarta: Penerbit ANDI.

Nuritomo. 2011. Pengaruh Peningkatan Penghasilan Tidak Kena Pajak (PTKP) Terhadap Penerimaan Pajak Studi Pada Kantor Pelayanan Pajak Yogyakarta Satu. Jurnal Ilmiah Akuntansi dan Bisnis Vol. 6 No. 1, Januari.

Resmi, Siti. 2013. Perpajakan, Teori dan Kasus Edisi 7. Buku 1. Penerbit PT Salemba Empat: Jakarta.

Sari, Diana. 2013. Konsep Dasar Perpajakan Cetakan Kesatu. Bandung: Refika Aditama.

Tunggal, Amin Wijaya. 2012. Pengantar Akuntansi Keuangan. Jakarta: Harvarindo.

Waluyo, 2011. Perpajakan Indonesia, Edisi10. Jakarta: Salemba. 